\title{
Beneficios y desafios ante un TLC con Estados Unidos
}

\author{
Un TLC con Estados Unidos \\ ofrece la oportunidad de acelerar \\ el ritmo de crecimiento \\ económico y empleo, ampliando \\ la base exportadora y los niveles \\ de inversión directa. Es necesario \\ prepararnos adecuadamente $y$ \\ trabajar en aumentar la \\ productividad para aprovechar \\ esta oportunidad.
}

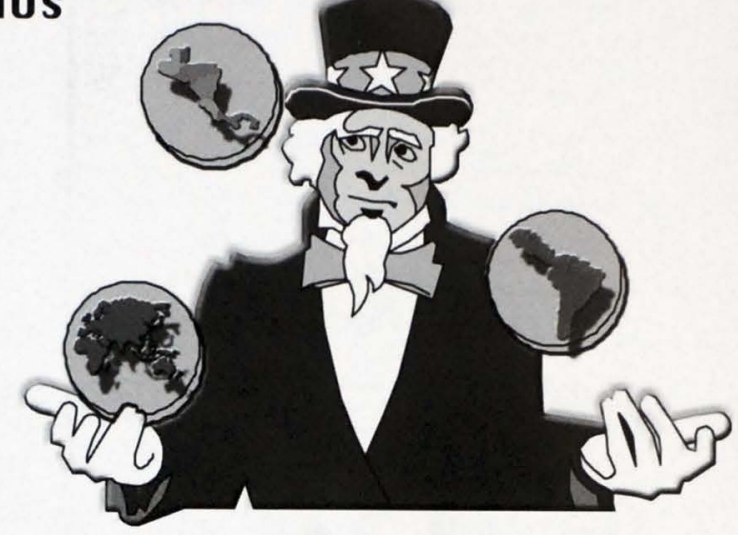

PRINCIPALES BENEFICIOS DEL TLC - USA

- Se contará con un instrumento permanente con reglas claras que garantice el libre comercio sin limite de tiempo, $y$ restricciones.

- Se logrará acceso preferencial al mercado más grande del mundo y que es nuestro principal socio comercial, y donde residen 2.2 millones de salvadoreños con capacidad adquisitiva para demandar nuestras exportaciones.

- Inversión Extranjera Directa y Alianzas Estratégicas. El solo anuncio de un TLC con USA vuelve al país un destino de interés para inversionistas extranjeros de instalar una fábrica en El Salvador con menores costos o de aliarse con empresas locales y accesar en condiciones preferenciales a mercados con los cuales existe libre comercio (México, C.A, Rep. Dom., Panamá, Chile).

- Los consumidores con la mayor competencia tendrán acceso a productos de calidad y a precios competitivos.

- El sector industrial podrá importar materias primas y bienes intermedios de calidad de los Estados Unidos con aranceles menores.

- Se mejoran las condiciones para atraer inversión extranjera al país en relación a México con NAFTA.

- La inversión extranjera directa y las alianzas estratégicas posibilitarán la transferencia de tecnología y el aumento de la productividad.

\section{RAMAS INDUSTRIALES CON POTENCIAL DE BENEFICIARSE CON EL TLC}

Industria Alimenticia

Papel Cartón y sus derivados

Industria Química y de medicamentos

Industria Textil y de Confección

Servicios Industriales de Maquila

Azúcar

Bebidas

Industria de Plástico

Productos Etnicos Artesanías.

\begin{tabular}{|c|c|c|c|c|c|}
\hline Atert & $\begin{array}{l}\text { Epportarionen } \\
\text { (Millowion } 5)\end{array}$ & 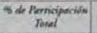 & 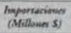 & $\begin{array}{c}\text { \$2 Perriciparion } \\
\text { Toud }\end{array}$ & 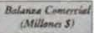 \\
\hline 1997 & 1,31250 & 56.8 & $1.975,80$ & 52,8 & -654 \\
\hline 1908 & $1+17>30$ & 524 & 2031.60 & 51.2 & $-5 s i s$ \\
\hline 1999 & 2.576 .50 & 62.8 & 2108.10 & 51.5 & .5326 \\
\hline $2 n 00$ & 1.95750 & 053 & 2050,30 & .25 & -5228 \\
\hline 2001 & 1.874 .80 & 65,4 & $2.46 a 50$ & 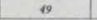 & 615,7 \\
\hline
\end{tabular}


Beneficios y Desafíos ante un TLC con Estados Unidos

Distribución de salvadoreños residiendo en Estados Unidos

\begin{tabular}{|c|c|c|}
\hline Estado & $\begin{array}{c}\text { Número de } \\
\text { Personas }\end{array}$ & $\%$ \\
\hline Washington D.C. & 150.000 & 7 \\
New, York & 421.000 & 19 \\
San Francisco, California & 450.000 & 20 \\
Los Angeles, California & 800.000 & 36 \\
Santa Ana, California & 85.000 & 4 \\
Miami, Florida & 75.000 & 3 \\
New Orleans & 9.600 & 0.4 \\
Houston, Texan & 92.000 & 4 \\
Chicago, Illinois & 72.000 & 3 \\
Boston, Massaclousset & 61.000 & 3 \\
& $2,215.600$ & 100 \\
\hline
\end{tabular}

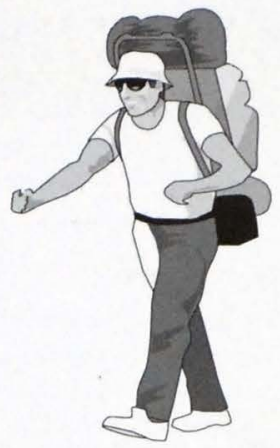

\section{PRINCIPALES DESAFIOS QUE IMPONE LA NEGOCIACION DEL TLC}

- Lograr un buen acuerdo, asimetría en los plazos de apertura, acceso inmediato para nuestros productos y 5 - 7 años para productos norteamericanos, así como la exclusión de algunos productos sensibles.

- Negociar el TLC como bloque regional Centroamericano dará fortaleza a la negociación y permitirá preservar nuestros mercados naturales.

- Modernizar la planta productiva nacional, para volverla más competitiva. Fortalecer la capacidad exportadora y de comercialización de nuestras empresas, investigación comercial, presentación del producto, adaptar los bienes a los gustos y exigencias de estos mercados.

- Las pequeñas y medianas empresas tienen baja capacidad de exportación, por lo que urge incrementar los niveles de asistencia técnica para apoyar el desarrollo y la competitividad de estas empresas y orientarlas a la internacionalización de sus productos.

- Mejorar algunos aspectos que nos hacen menos comperitivos frente a otros países como: seguridad jurídica, seguridad ciudadana, mano de obra capacitada, red de infraestructura física, precio de energía eléctrica, costo del transporte - flete.

- En casos de productos con apoyos y subsidios de USA en que exista producción nacional (arroz, lácteos, piezas de pollo), mantener estados de protección vigentes mientras subsistan.

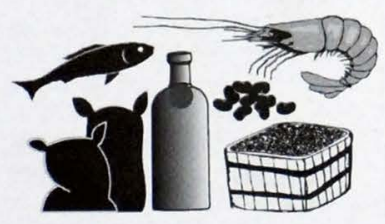

Entorno

Principales exportaciones a Estados Unidos 1998 - 2000 (Millones US\$, no incluye maquila)

\begin{tabular}{|c|c|c|c|c|c|c|}
\hline Broducto & $\begin{array}{c}2000 \\
\text { Valor (USS) }\end{array}$ & $\%$ & $\begin{array}{c}1999 \\
\text { Valor (USS) }\end{array}$ & 96 & $\begin{array}{c}1998 \\
\text { Valor (USS) }\end{array}$ & $\%$ \\
\hline Filete congelado de curvina & 1,235 & 0.6 & 0.014 & 0.0 & n.d & 0.0 \\
\hline Camarones frescos & 14,691 & 7.4 & 23,820 & 17.5 & 30,714 & 19.1 \\
\hline Hortalizas & 1,392 & 0.7 & 0.098 & 0.0 & 0.038 & 0.0 \\
\hline Frijoles & 2,185 & 1.1 & 1,921 & 1.4 & 1,622 & 1.0 \\
\hline Cafe oro & 140,522 & 70.4 & 68,543 & 50.4 & 86,403 & 53.7 \\
\hline Ajonjoli & 2,333 & 1.2 & 2,069 & 1.5 & 2,395 & 1.5 \\
\hline Azuicar de caña & 13,131 & 6.6 & 18,222 & 13.4 & 25,521 & 15.9 \\
\hline Melazan de caña & 2,351 & 1.2 & 2,790 & 2.1 & 3.258 & 2.0 \\
\hline Cerveza de malra & 3,068 & 1.5 & 1,024 & 0.8 & 0.698 & 0.0 \\
\hline Alcobol etsilico absoluto & 6,075 & 3.0 & 6,876 & 5.1 & 3.973 & 2.5 \\
\hline Velas (catndelas) & 5.554 & 2.8 & 3.573 & 2.6 & 672 & 0.4 \\
\hline Carteras de plastico & 1,888 & 0.9 & 2,545 & 1.9 & 2.531 & 1.6 \\
\hline Sacos, blsitas y cucurucbos de papel & 3,877 & 1.9 & 2,853 & 2.1 & 2,479 & 1.5 \\
\hline Hilos, menzas y cables de cobre & 1,304 & 0.7 & 1,672 & 1.2 & 1,285 & 0.8 \\
\hline Toual & 199,606 & 100.0 & 135,908 & 100.0 & 160,863 & 100.0 \\
\hline
\end{tabular}

